\title{
Attracting small-town docs a challenge
}

$\mathrm{T}$ he federal government of Canada's plan to forgive student debt for family doctors intending to practise in rural communities will help increase the pool of rural physicians but a larger suite of solutions is required, say educators and rural doctors.

Doctors will qualify for up to $\$ 8000$ per year for five years in forgiveness from the Canada Student Loan Program under the federal initiative to forgive a portion of student loans for family doctors, nurses and nurse practitioners working in rural communities, which was announced in August by Dr. Kellie Leitch, parliamentary secretary to Human Resources Minister Diane Finley. The program will commence in spring 2013.

Manitoba Health Minister Theresa Oswald praised the plan as an investment that "complements the programs and initiatives already in place to and recruit and retain doctors and nurses in rural Manitoba."

Viewing loan forgiveness as one piece of the strategy on how to attract and retain rural doctors is exactly right, according to leading educators. They believe Canada needs a systematic policy framework to tackle the problem, involving key players including faculties of medicine, provincial governments, the Royal College of Physicians and Surgeons of Canada, the College of Family Physicians of Canada and physicians' associations.

"I think every little bit helps, but I don't think it will solve the problem," says Dr. David Snadden, executive associate dean of education for the faculty of medicine at the University of British Columbia in Vancouver. "It's a very complex kind of equation."
Health service reform is an important component of attracting and retaining rural doctors, many of whom seek salaried appointments rather than fee-forservice funding and an interdisciplinary team to work with, as well as remuneration for night and weekend work and hospital service, Snadden says.

Ensuring that medical students and residents are exposed to rural and northern practices, selecting medical students from rural backgrounds, building relationships at "distributed" medical campuses outside of large urban environments, and creating nontraditional funding and support arrangements in rural practices are also critical pieces of an overall strategy, say Snadden and Dr. James Rourke, dean of medicine at Memorial University in St. John's, Newfoundland and Labrador.

The way a rural community welcomes

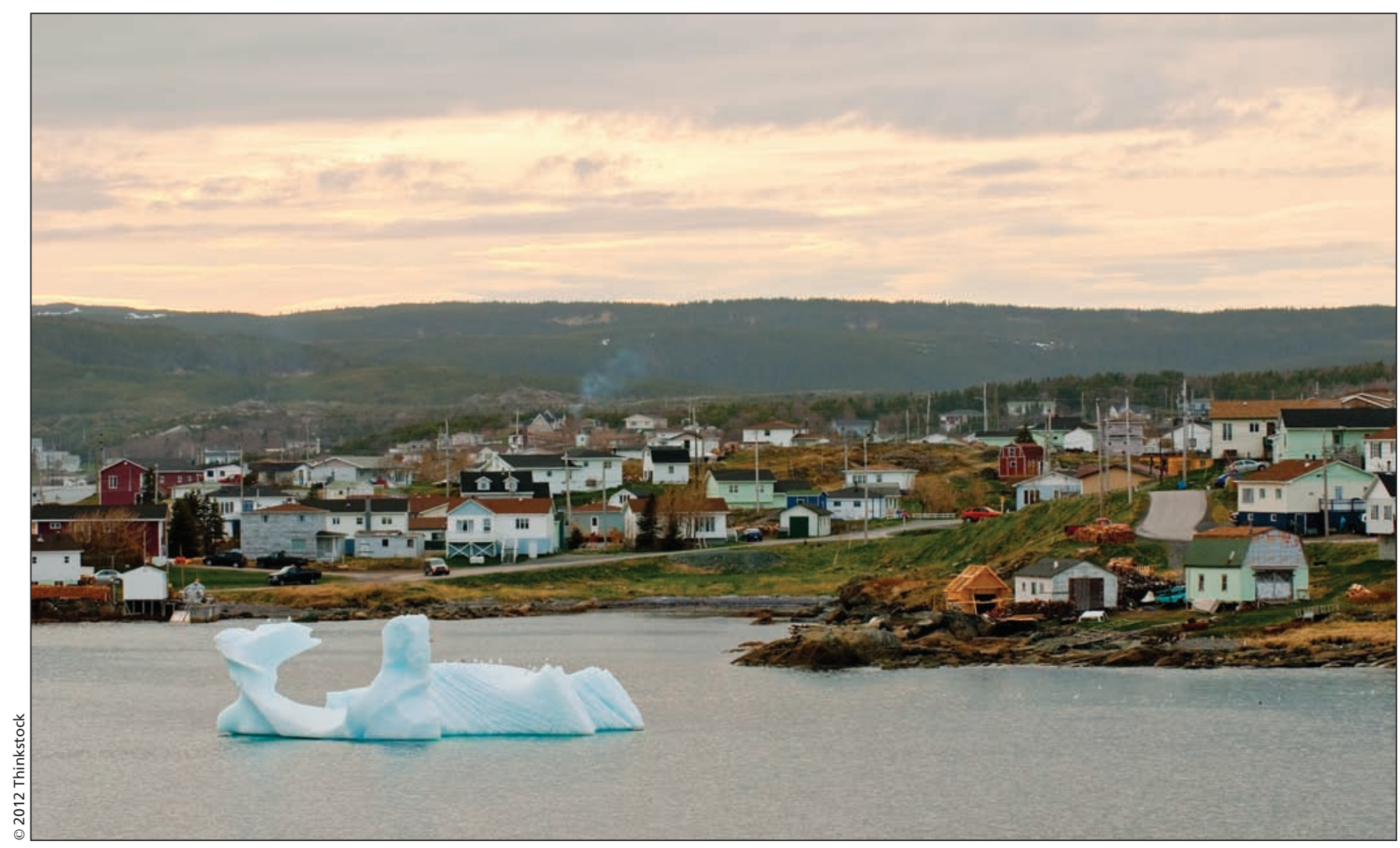

Physicians educated in Newfoundland and Labrador are among the most likely in Canada to be practising in rural areas a decade after graduation. 
a new physician, commitment to coverage for holidays, time off, continuing medical education and the regional support network for transferring patients who need additional care to larger centres are also important for rural doctors, as Dr. James Card attests.

Card, a family physician in Mackenzie, BC, says the welcome the town gave him and wife Jessica was a vital factor in their decision to move to the community, which is about 200 kilometres north of Prince George, BC. "It was incredible," he says. "The mayor made me a quilt! The community is very wellorganized. There's lots going on. There's lots to do and we're quite happy."

Card believes loan forgiveness might tip the balance in favour of rural practice for some physicians, but only in the short-term, after which they are likely to move to urban centres. "You do not create a rural doctor, you train a rural doctor," he says. "I honestly think it starts with recruiting the right people to medical school in the first place."

As an outdoor enthusiast who spent much of his early career tree-planting across the province, Card was already inclined to rural practice when he attended medical school at the University of Northern British Columbia in Prince George.

His experience fits what the research has demonstrated, say educators. "We know that in terms of getting people into rural practice, what's still a major deter- minant is where people come from in terms of their upbringing," says Rourke.

Depending upon how one defines "rural," about $20 \%$ of the Canadian population lives in a rural area, but only about $11 \%$ of medical students come from rural backgrounds, says Rourke. Yet there is solid evidence worldwide that students from rural backgrounds are two to five times more likely to go into rural practice than their urban counterparts, he says.

In another way of defining the problem, towns with fewer than 10000 people support $22 \%$ of the Canadian population but are served by only $10 \%$ of physicians, according to the Society of Rural Physicians of Canada. Among Canadian doctors who are in rural practice, about one-third come from rural backgrounds, one-third from small cities and one-third from metropolitan areas, Rourke adds.

"That's why one needs a comprehensive approach," says Rourke. "The concept described by several people in rural practice is the idea of a 'pipeline'."

That pipeline approach, which Memorial University of Newfoundland and Labrador in St. John's has adopted, involves reaching out to high school students, Aboriginal students and other specific populations to encourage them to consider medical school with a particular focus on serving rural and remote populations.

Memorial has not only concentrated on admitting medical students from rural backgrounds, the university has made rural medicine a core part of its curriculum in each year, giving students opportunities to spend substantial time in rural areas. Rural physicians are involved in all aspects of curriculum development and the family medicine residency program is heavily rurally focused and based, Rourke says.

As a result, $30 \%-40 \%$ of medical students admitted each year are from rural backgrounds, and Memorial received the Keith Award from the Society of Rural Physicians of Canada in 2010 for the highest percentage of rural graduates practising in rural areas 10 years after graduation.

At the University of Northern BC's medical school, about $90 \%$ of graduates from the first two years of the family presidency program are in rural or northern practices, says Snadden.

Overall, Canada has made limited progress in admitting more medical students from rural backgrounds and good progress in increasing rural exposure during medical school and residency, but only patchy progress on providing financial incentives, infrastructure and support staff and regional support for patient transfers, says Rourke.

"I think there is a realization that this is a problem that's being worked on, but it's not done." - Laura Eggertson, CMAJ.

CMAJ 2012. DOI:10.1503/cmaj.109-4280 